\title{
Jubilee Celebrations of the Society of Chemical Industry.
}

THE celebration of its jubilee by the Society of 1 Chemical Industry will long remain as a landmark in the history of both pure and applied science, and as a very convincing demonstration of the progressive narrowing of the gap between industry and pure research. The members of the Society were welcomed at the inaugural ceremony at Guildhall by the Lord Mayor of London and the Vice-Chancellor of the University of London. The close association which has always existed between the Corporation and the livery companies of the City and chemical education and research was manifested by the presentation of plaques and addresses to a number of the companies. The importance of chemical technology in this industrial age will render the meeting a not unimportant event even in the long history of Guildhall.

The first day of the celebration was marked also by the opening of the British Chemical Plant and Research Instruments Exhibition by the president of the Society, Sir Harry McGowan. A similar exhibition has not been held since 1926, and the progress made during the past five years in the application of pure metals such as aluminium, nickel, and silver, of stainless iron and stecl, and of special alloys, is very striking; although it cannot yet be said that an alloy may be selected to meet any given set of requirements relating to corrosion resistance, ease of working, and mechanical strength, nevertheless such an ideal state is approaching rapidly. Methods of fabricating plant have also made strides, largely as a result of the work carried out by the British NonFerrous Metals Research Association on the welding of, especially, copper and special alloys ; of particular interest was what is believed to be the first public exhibit of welded copper plant. Despite these developments, fused silica is still making progress and widening its scope and the size of unit available; recent productions include a valveless plunger pump, a water-driven gas injector, and a new type of lamp in which the shorter wave-length rays of the quartz mercury arc are utilised to produce ozone but are removed from the light by a filter in order to obviate danger to the eyes. New aids for the laboratory were represented by the Meta-filter, a continuously operating still for the production of conductivity water, stainless steel and iron apparatus, and a flow meter for gases at high pressure; a notable demonstration was that of the cinematographic method of studying crystal growth, which should be of considerable value to the research worker and to the industrial chemist.

A special section of the exhibition was arranged by the Chemical Engineering Group to illustrate some of the work carried on by the Department of Scientific and Industrial Research and the various industrial research associations. One of the most important advances made in physico-chemical science during the past decade or so, namely, the investigation of structure by means of $X$-rays, was illustrated in its technical applications by a variable anticathode X-ray tube and some forms of X-ray spectrograph designed for studying the change of structure of alloys on heat treatment and cold working, and for examining such materials as rubber and wool. Other exhibits in this section included a quartz spectrograph for the routine quantitative analysis of metals and alloys, apparatus for testing the surface conductivity of materials such as ebonite, for measuring plasticity and plastic yield, and for bringing about artificial weathering and ageing. The development of the chemical autoclave from Papin's digester of
1681 to the modern vessel, which, thanks to special forged alloy steels, is capable of being used at several hundred atmospheres pressure and at temperatures up to $450^{\circ} \mathrm{C}$., formed the subject of a series of drawings and exhibits by the National Physical Laboratory. The products of high pressure synthesis shown included hydrogenation products of low temperature tar, reduction products of fluorine compounds, and a variety of condensation products.

Other activities of the Chemical Research Labora. tory at Teddington, demonstrated when the laboratories were opened for inspection by the members of the Society, related to the investigation of tars, the production of synthetic resins, and to studies on the corrosion and protection of metals, and notably the protection of aluminium by anodic oxidation and of magnesium alloys by films of selonium. An attractive collection of co-ordination compounds, chemotherapeutic substances, and chemicals of historic interest, such as organic antimonials and arsenicals, were also on view.

One of the most valuable of the week's activities, and one which merits wider attention than that of those direct]y engaged in the relevant industries, was the discussion of a series of papers on fuel, selected by the Fuel Committee. The paper by Dr. C. H. Lander summarised the present position of Great Britain with regard to fuel supplies, and discussed the economic practicability of the hydrogenation of coal and of the production of our oil fuel requirements by this process and, to a limited extent, by pre-carbonisation of some of the coal which is now burned in its raw state. The application of hydrogenation to the treatment of petroleum residues is regarded by Dr. A. E. Dunstan, of the Anglo-Persian Oil Co., as a definite technical success, although its objective is no longer the production of petrol, but of, for example, lubricating oils from low grade stocks; the relative values of the refinery products are bound to alter in the not very distant future, when petrol is ousted from its present premier position by the development of the high-speed Diesel engine. It appears likely that a by-product industry, based on petroleum and comparable in magnitude with that based on coal tar, will become established during the next few years as a result of the increasing utilisation of refinery gases and gases obtained by cracking for the production of solvents such as glycols, esters and alcohols, and of 'anti-knock' substances; the growing demand for asphalte for road use and of carbon black for mubber manufacture is also of importance in this connexion. The future of fuel is a controversial subject, but it seems clear that the production of oil from coal in quantities sufficient to meet the demands of Great Britain is, at the moment, economically impossible; but the striking and constantly increasing yields of oil which are now obtained suggest that the processes available may compete seriously if and when oil prices rise from their present abnormally low values.

Another aspect of the same problem was presented by Mr. Taylor in his paper on the production of liquid fuels from water gas. The most promising of the many processes which have been investigated is that of $F$. Wischer, which yields $75-80$ per cent of the calorific value of the water gas as hydrocarbons; this yield corresponds with about twenty-five per cent of the heat value of the coke required for the production of the gas. Although processes of this type resemble hydrogenation in being economically impracticable at the moment, it is probable that when

No. 3221, VoL. 128] 
the price of petrol rises, more direct and therefore cheaper methods will have been perfected. Other important papers in the fuel section included that by Prof. R. V. Wheeler on gaseous combustion, which dealt with the industrial applications of recent research work on the combustion of gases, and especially on flame propagation and the influence of diluents; and papers on low temperature carbonisation, the utilisation of low temperature tar, and fuel developments in iron and steel practice. A closely related subject, at least from the theoretical aspect, was dealt with in Prof. Wheeler's lecture on a subject of both academic interest and increasing technical importance, namely, dust explosions-delivered, very appropriately, at the Home Office Industrial Museum

Sir Harry McGowan's presidential address dealt mainly with the reaction of scientific progress on the finance and economy of the modern State, and constituted an opportune appeal for economic unity between the nations of the Empire, for still greater unification of the various industries of each country, and for a deeper appreciation of the economic background of all industrial activity. The address by Dr. H. Levinstein, on the occasion of the presentation to him of the Society's medal, urged that the lessons to be learned from the history of the dyestuffs industry should be taken to heart by other national industries, and that the 'buy in the cheapest market' maxim should be reconsidered.

Dr. G. Engi, conveying the congratulations of the Society of Chemical Industry in Basle in an address delivered at the Salters' Hall, gave an account, in considerable detail, of recent developments in both the scientific and terchnical aspects of the chemical industry in Switzerland. The development of the dyestuffs industry in that country has resulted largely from fertile inventive activity and a reasonable degree of rationalisation; recent developments include the production of thioindigo dyes of the naphthalene series, of vat dyes obtained by introduction of the cyanuric ring into the anthraquinone molecule and by the synthesis of indigoid and thioindigoid derivatives of the anthracene and anthraquinone series, and of complex chromium and copper azo-dyes. Important advances have been made also in connexion with pharmaceutical products, synthetic resins, textile chemistry, and electrochemical processes. Addresses were given also by two of the new honorary foreign members of the Society, that by Dr. Sørensen dealing with hydrogen ion concentration, and that by General G. Patart with the technique of gaseous syntheses at high pressure; the development of, for example, synthetic methanol demands considerable reduction of costs, which, since the raw materials are available at almost zero cost, must be concerned mainly with the plant and equipment used. The large part played by catalysis in this type of reaction, however, necessitates improved methods of purification of the raw materials in order to remove " poisons ', and further work on the preparation of highly active catalysts. The importance of the outlets for these synthetic products justifies continued research and the expenditure of relatively large sums of money.

The very full programme for the jubilee week was completed by a series of visits to factories engaged in the chemical and related industries and to various research laboratories, and by a number of purely social functions.

\section{Congress of Universities of the Empire, r93I.}

THE congress of the seventy universities of the 1 British Empire began its official programme in London on July 1 and continued its work in Edinburgh on July 6-11. On July 3 in Guildhall--" the centre of the Empire in London, which has been for centuries a financial, and is this day an educational clearing-house of the world "-H.R.H. the Prince of Wales in his address of welcome as president of the Congress observed that "one of the things the world requires most to-day is organised knowledge and the means of distributing it ". This truth crystallised in a sentence world necessities in a time of crisis. Pope said a little learning, not a little knowledge, was a dangerous thing; and assuredly in these days it is not learning which the peoples of the world require. They have enough of that from the popular press and the politician.

That millions are anxiously seeking "the two noblest things, sweetness and light" in the matter of post-War reconstruction, presented to the Empire universities an opportunity of discussion and decision on the question of the best method of disseminating organised knowledge and of promoting a closer co-ordination of their activities so as to ensure that they play their part in bringing order out of chaos. It was realised by all who participated. in the work of Congress that it is in the universities, and possibly in the universities only, that the problems of to-day and the policy of to-morrow can be examined with that detachment of view, that width of judgment and that patience of understanding which alone will ensure their solution, and that these centres of knowledge must become more and more the training grounds of the young men and women who will have to do the work of the Commonwealth in the future. Lord Meston presented this point of view in another form when he said that there were certain things, essential to the well-being of their peoples, which he believed their universities were doing, which ought to be done by their universities and which could not be done systematically except by their universities. It was further realised that universities, any more than individuals, cannot live to themselves alone. The social functions-a natural and necessary part of the work of a congress of this kind--contributed to the formation of friendships, the creation of mutual understanding and trust and to that action and interaction of minds which, in Burke's words, "draw out the harmony of the universe". From every part of the Empire an instinctive desire for closer association was revealed.

Universities, however, are naturally jealous of their autonomy. Sometimes, perhaps, they are disposed to convert their conceptions of autonomy into a fetish. It is, none the less, a condition of their very existence that they should be responsible neither to individuals nor to the State for the direction of their affairs. They must develop along the lines set by tradition, by geographical accident, and by their charters. It will be a tragedy if that independence which the universities have rightly and sacredly cherished is sacrificed to expediency or to financial necessity. Not even the benefactions of the wealthy must detract from the purposes for which they have been established and which they must subserve.

The calm of the cloisters has, in these post-War years, however, been disturbed by repercussions from world polities, and in his observation that Imperial necessities demanded from the universities support of the Universities Bureau of the British Empire, the Vice-Chancellor of Manchester lifted a discussion on financial commitments out of the sphere of self-

No. 3221, VoL. 128] 